François Feihl

Alain F. Broccard

\section{Interactions between respiration and systemic hemodynamics. Part I: basic concepts}

Received: 31 October 2007

Accepted: 26 August 2008

Published online: 30 September 2008

(C) Springer-Verlag 2008

The second part of this article is available at: doi:10.1007/s00134-008-1298-y.

\section{F. Feihl}

Division of Clinical Pathophysiology, University Hospital (CHUV) and Lausanne University (UNIL), 1011 Lausanne, Switzerland

\section{A. F. Broccard}

Medical Intensive Care Unit, Regions Hospital Pulmonary and Critical Care Division, Regions Hospital, St Paul, MN 55101-2595, USA
F. Feihl (®)

Division de Physiopathologie Clinique, Centre Hospitalier Universitaire Vaudois, BH10-701, 1011 Lausanne, Switzerland e-mail: Francois.Feihl@chuv.ch

Tel.: +41-21-3141423

Fax: +41-21-3141432

\begin{abstract}
The topic of cardiorespiratory interactions is of extreme importance to the practicing intensivist. It also has a reputation for being intellectually challenging, due in part to the enormous volume of relevant, at times contradictory literature. Another source of difficulty is the need to simultaneously consider the interrelated functioning of several organ systems (not necessarily limited to the heart and lung), in other words, to adopt a systemic (as opposed to analytic) point of view. We believe that the proper
\end{abstract}

understanding of a few simple physiological concepts is of great help in organizing knowledge in this field. The first part of this review will be devoted to demonstrating this point. The second part, to be published in a coming issue of Intensive Care Medicine, will apply these concepts to clinical situations. We hope that this text will be of some use, especially to intensivists in training, to demystify a field that many find intimidating.

Keywords Heart-lung interactions . Cardiovascular issues in the ICU . Cardiovascular monitoring . Mechanical ventilation, complications · Mechanical ventilation, weaning

\section{Historical note}

The earliest description of cardiorespiratory interactions may be traced back to the first invasive measurement of arterial blood pressure, carried out by Stephen Hales. In the early eighteenth century, this renowned English physiologist inserted a glass tube into the carotid artery of a mare and noted that the height of the column of blood fluctuated with the animal's respiratory efforts. Hales did not stop at describing these fluctuations, but he also theorized on the possible effects of respiration on venous return [1]. Many of the concepts which underly our current understanding of cardiorespiratory interactions were already in place at the start of the twentieth century. For example, the idea that the fall in pleural pressure could impede left ventricular ejection during inspiration was put forward by Donders in 1853, and Riegel mentioned the potential role of this mechanism in the pathogenesis of pulsus paradoxus in 1903 [1].

However, the diffusion and extension of this new knowledge had to await the need for practical applications. The first one arose during World War II, when the US Air Force sought to enhance the ability of its pilots to fly at very high altitude in airplanes with unpressurized cockpits. In these conditions, hypoxia was the limiting factor. It was calculated that every $5 \mathrm{~cm} \mathrm{H} \mathrm{H}_{2} \mathrm{O}$ of pressure 
added selectively to the face mask supplying the pilot with $100 \%$ oxygen would increase the maximal tolerable altitude by 1,000 feet $[1,2]$. To clarify the possible adverse effects of such positive pressure breathing, the US Air Force sponsored studies by several groups of prominent physiologists, in particular Rahn and Fenn as well as Carr and Essex. These studies clearly described the effects of pressure breathing on intramural vascular pressures and cardiac output [2-4]. In the late 1940s, seminal work conducted by Cournand and colleagues at Columbia University demonstrated the major role of a reduction in right ventricular transmural filling pressure in the depression of cardiac output caused by positive

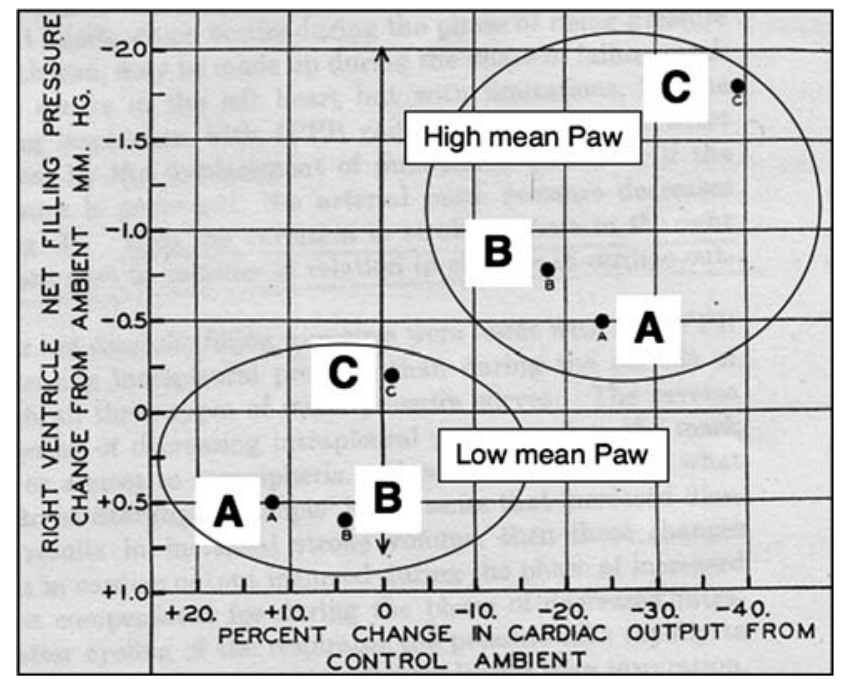

Fig. 1 Some of Cournand's original data showing a direct relationship between the effects of intermittent positive pressure breathing (IPPB) on right ventricular filling pressure and on cardiac output. $A, B$, and $C$ designate three individual patients, with two data points for each. The right ventricle was catheterized. IPPB was administered via a face mask. Due to the presence of a therapeutic pneumothorax, pleural pressure could be easily obtained. In stable ventilatory conditions, right ventricular end-diastolic pressure and pleural pressure (both measured relative to atmosphere) were averaged over one full respiratory cycle, and the difference of these two values indicated right ventricular net filling (i.e., transmural) pressure. Cardiac output was measured with the direct Fick method. The abscissa indicates the change in cardiac output observed when switching from spontaneous breathing (SB, i.e., ambient pressure in face mask) to IPPB, expressed in \% of the baseline value in SB. The ordinate shows the concomitant change in right ventricular end-diastolic transmural pressure (in $\mathrm{mm} \mathrm{Hg}$ ). Note the inverted scale of both axes. The 3 points on the upper right part of the plot (which indicate that a large decrease in transmural filling pressure was associated with a marked depression of cardiac output) were obtained when switching from SB to a pattern of IPPB with a high I/E ratio $(>1)$ and some positive end-expiratory pressure $(3 \mathrm{~cm}$ $\mathrm{H}_{2} \mathrm{O}$ ), thus inducing a relatively large increase in mean airway pressure $\left(P_{\mathrm{aw}}\right)$. The group of 3 points on the lower left correspond to a switch from SB to IPPB with an I/E ratio $<1$ and no positive end-expiratory pressure, a pattern which raised mean $P_{\mathrm{aw}}$ to a lesser extent, and neither decreased transmural filling pressure nor depressed cardiac output. Reproduced from [5], with permission from the American Physiological Society pressure mechanical inflation (Fig. 1) [5]. In the following years, Guyton provided a theoretical framework of particular relevance to these observations [6]. This framework remains important to our present understanding of cardiorespiratory interactions. It will now be shortly presented.

\section{Guyton's description of integrated cardiocirculatory function}

\section{Venous return curve}

The term capacitance vessels designates the highly distensible vessels of the circulatory system, in practice largely the veins (Chap. 10 of [6]). The veins, and especially the small veins [7], contain the major fractionapproximately $70 \%$ - of the total systemic blood volume. They are not only highly distensible, but also contain substantial volume even when their transmural pressure is near zero, that is, they have a large unstressed volume. Magder $[8,9]$ has proposed a representation of venous capacitance as a reservoir drained through an opening in the side rather than the bottom (Fig. 2a). The liquid below the opening represents the unstressed volume, which cannot escape from the system. The amount of liquid above the opening is the stressed volume, which alone generates a pressure known as the mean systemic filling pressure (MSFP). The blood flow from the reservoir to the heart, i.e., the flow of venous return $\left(Q_{\mathrm{RV}}\right)$, is governed by the equation

$$
Q_{\mathrm{RV}}=(\mathrm{MSFP}-\mathrm{RAP}) / R_{\mathrm{v}}
$$

where MSFP and RAP (right atrial pressure) are measured relative to atmosphere, and $R_{\mathrm{v}}$ is the resistance to venous return. Thus, the numerator of Eq. 1 is the pressure gradient which drives venous return. If MSFP and $R_{\mathrm{v}}$ remain constant, it can be seen from Eq. 1, that $Q_{\mathrm{RV}}$ must increase when RAP decreases. However, if RAP is lowered below a critical pressure $\left(P_{\text {crit }}\right)$ normally close to atmospheric, the transmural pressure of the great veins at the thoracic inlet becomes negative, leading to their collapse which prevents any further increase in $Q_{\mathrm{RV}}$ (flow-limitation). From this overall state of affairs, it results that the relationship between $Q_{\mathrm{RV}}$ and RAP at constant MSFP has the shape depicted by curve 1 in Fig. 2b. Guyton has coined the term venous return curve for this relationship. His classical experiments in dogs where right ventricular bypass was used to uncouple venous return from cardiac output have provided a strong support for this model. In particular, the linearity of the venous return curve for values of RAP above $P_{\text {crit }}$ has been confirmed ${ }^{1}[10]$. The venous return

\footnotetext{
${ }^{1}$ A minor departure of experimental data from Eq. 1, the junction of the horizontal and steep part of actual venous return curves is smooth rather than angular, suggesting a distribution rather than a unique value of $P_{\text {crit. }}$.
} 
A
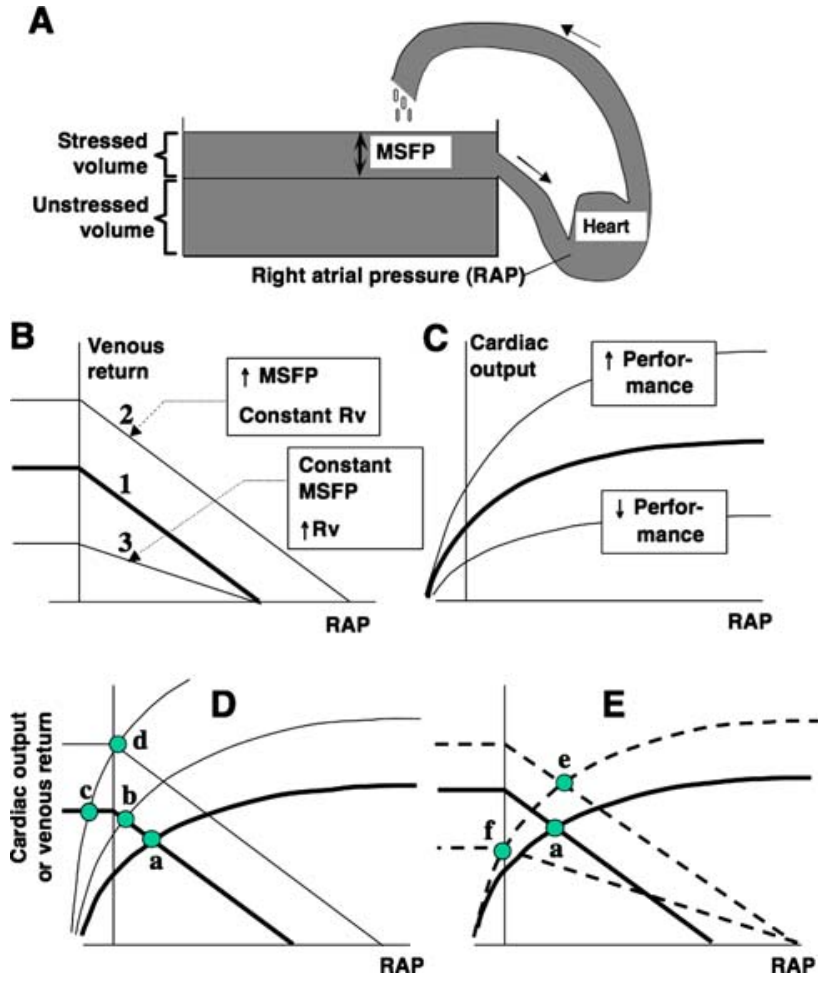

Fig. 2 Interactions of venous return and cardiac function. a Magder's representation of the circulatory system. Modified from [8], with permission. MSFP mean systemic filling pressure. Detailed explanations in the text (beginning of Sect. "Venous return curve"). b Venous return curves (later part of Sect. "Venous return curve"). c cardiac function curves (Sect. "Cardiac function curve"). d Guyton's graphical analysis of cardiac output regulation (Sect. "Graphical analysis of cardiac output/venous return"). e Potential effects of generalized venoconstriction on cardiac output (last paragraph of Sect. "Graphical analysis of cardiac output/venous return"). In panels b-e, RAP designates right atrial pressure relative to atmosphere

curve intercepts the horizontal axis at a pressure value equal to MSFP. This statement implies that RAP equals MSFP in circulatory arrest, forming the basis for the experimental measurement of MSFP. At constant $P_{\text {crit }}$ and $R_{\mathrm{v}}$, any increase in MSFP, whether due to an augmentation of the total blood volume in the capacitance vessels or to a transfer of blood from the unstressed to the stressed volume (the latter often resulting from venoconstriction due to adrenergic stimulation), translates into an "rightward" shift $^{2}$ of the venous return curve (Fig. 2b, curve 2). Conversely, hypovolemia, whether absolute or relative (i.e., reduced venous tone leading to increased venous compliance and transfer of blood from the stressed to the

\footnotetext{
2 "Rightward" is enclosed in quotes for the following reason: with a true rightward shift of the venous return curve, i.e., a horizontal translation in the narrow geometric sense, $P_{\text {crit }}$ would increase and maximal venous return would not change. This would not be consistent with the differences between curves 1 and 2 shown in Fig. 2b.
}

unstressed volume) would shift the venous return curve "leftwards" (not shown on Fig. 2b). Finally, let us note that the slope of the linear part above Pcrit is inversely related to $R_{\mathrm{v}}$ (Fig. 2b, curve 3$)^{3}$.

\section{Cardiac function curve}

In Guyton's representation, the cardiac function curve is a plot of cardiac output against the intramural RAP (Fig. 2c). As such, it is "a composite function curve for the entire segment of the circulatory system between the input of the heart and its output, including, of course, both sides of the heart as well as the pulmonary circulatory system" (Chap. 8 of [6]). The position of the cardiac function curve depends on, and in fact integrates, all aspects of cardiac pump performance, including the diastolic function, contractility and afterload of both ventricles, as well as heart rate.

Let us insist that, despite transmural pressure being a better index of cardiac preload, the RAP depicted in Fig. $2 \mathrm{c}$ is intramural pressure, i.e., measured relative to atmosphere, as is the case for the venous return curve in Fig. 2b. Why this is so will become clear in an instant.

\section{Graphical analysis of cardiac output/venous return}

Both the venous return and the cardiac function curves express flow as a function of intramural RAP, and may therefore be superimposed on the same plot (Fig. 2d). Over any time frame longer than a few heartbeats, cardiac output must equal venous return, i.e., the heart can only pump what it receives from the periphery. Thus, systemic blood flow is indicated by the intersection of the cardiac output and venous return curves, which is designated as the operating point of the circulatory system for specific states of vascular and cardiac function. In spite of its simplicity, this representation has considerable heuristic value for the integrated analysis of cardiovascular events. For example, an instantaneous increase in cardiac output cannot influence MSFP because of the large compliance of capacitance vessels. Therefore, the only way that an augmentation of ventricular performance may cause a steady increase of venous return is by lowering RAP (Fig. 2d, operating point displaced from a to b). When RAP decreases below $P_{\text {crit }}$, the operating point becomes located on the horizontal part of the venous return curve, so that circulatory flow becomes independent of cardiac function (Fig. 2d, point c) although it may

\footnotetext{
${ }^{3} R_{\mathrm{v}}$ is not a simple function of venous geometry and blood rheology, but depends in addition, and nonintuitively, on the distribution of blood flow between parallel vascular beds of different time constants [11]. Hence, its designation as resistance to venous return rather than venous resistance.
} 
increase if peripheral determinants of venous return change in the appropriate direction (for example if MSFP is augmented and the venous return curve is shifted "rightwards" following i.v. fluid administration, Fig. 2d, point d).

We have so far ignored potential changes in the resistance to venous return $\left(R_{\mathrm{v}}\right)$. For example, venoconstriction induced by a sympatho-adrenergic discharge may both reduce venous compliance (thus increasing MSFP) and augment $R_{\mathrm{v}}$ (thus "flattening" the oblique part of the venous return curve, see end of Sect. "Venous return curve" and Fig. 2b). The net impact on the position of the operating point, and thus on cardiac output, then depends on the balance between these two conflicting influences, as shown in Fig. 2e, where the plain curves represent the baseline state (operating point a), and the dashed curves, the effects of sympatho-adrenergic stimulation, assuming either a small (point e) or large (f) increase in $R_{\mathrm{v}}$ for the same change in MSFP.

\section{Three caveats}

The graphical analysis presented above is conceptually quite useful, as we hope to demonstrate in subsequent sections. However, it may be a source of confusion if incompletely understood. The first confusion arises if it is not clearly noted that the intramural RAP relative to atmosphere is being used throughout. Thus, the Guytonian cardiac function curve is shifted to the left or to the right by a decrease or an increase in extramural (intrathoracic) pressure (Sect. "Contact interactions of the heart and lungs" in Part I and Sect. "Effects of PEEP on cardiac output" in Part II). The second confusion relates to the intellectual habit of considering a variable plotted in abscissa as necessarily independent. For example, it is commonly considered that i.v. fluid loading increases cardiac filling pressures (thus RAP), hence cardiac preload, hence cardiac output. Considering Fig. $2 b$ which predicts that venous return should decrease with a increasing RAP, one might feel faced with a conundrum. The solution is of course that vascular filling first increases MSFP, which augments venous return, which increases cardiac preload and filling pressures. In such conditions, MSFP must always increase more than RAP does, otherwise venous return could not be augmented. In general, RAP can only be independently controlled if the heart is uncoupled from venous return by interposing an external

\footnotetext{
${ }^{4}$ By considering Fig. 2d, the geometrically-minded reader might note that intravascular volume expansion, translated into a "rightward" shift of the venous return curve, necessarily leads to a smaller increase in RAP than in MSFP if the heart operates on the ascending part of its function curve (i.e., if cardiac output is preload-dependent).
}

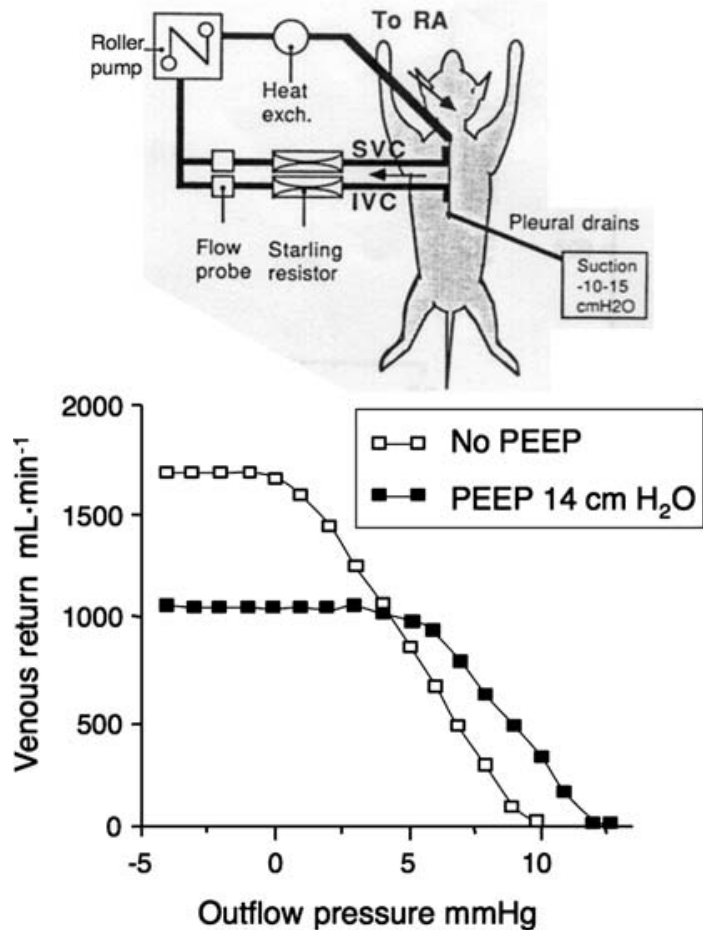

Fig. 3 Effects of PEEP on the venous return curve in closed-chest canines. Dogs were anesthetized, intubated and ventilated. By ways of cannulas placed in both venae cavae, venous return was drained through Starling resistors (i.e., collapsible tubes enclosed in an airtight chamber to allow control of their extramural pressure), and pumped back into the right atrium $(R A)$ with a roller pump (upper part of the figure). The pump rotating speed was set so as to maintain a negative intramural pressure within the collapsible tubes. In such conditions, the pump forwarded into the heart and circulation whatever amount of blood came through the Starling resistors, independent of heart function (i.e., venous return would be uncoupled from heart function). By adjusting the extramural pressure around the collapsible tubes, outflow pressure for venous return (the equivalent of right atrial pressure in the intact organism) could be set at any desired value, and the resulting venous outflow was then measured. In this way, the venous return curves shown in the lower part of the figure were constructed at two different PEEP levels, after surgical closure of the chest (from [25] with permission). These data are discussed in detail in Sect. "Respiration and venous return". Outflow pressure is measured relative to atmosphere

bypass circuit, as Guyton (Sect. "Venous return curve") and others (Sect. "Contact interactions of the heart and lungs", Figs. 3, 4) have done experimentally. In the intact organism, by contrast, RAP is no more an independent variable than are venous return or cardiac output. The third confusion consists in a semantic ambiguity of the expression "venous return", which designates either the flow of venous return (in liters of blood per minute) or the physiological function depicted by the venous return curve. In the case of the heart, such ambiguity does not exist (i.e., usual terminology always clearly distinguishes heart function from cardiac output). 


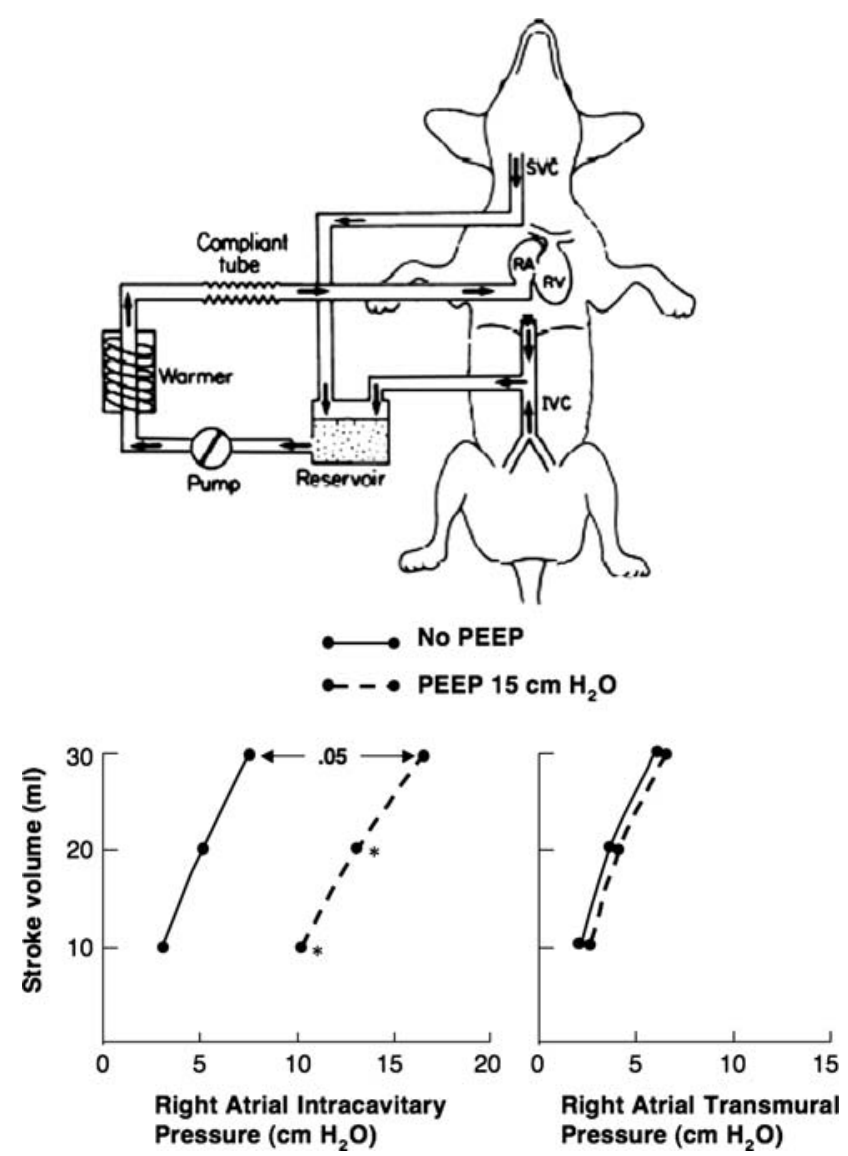

Fig. 4 Effects of PEEP on the cardiac function curve in closedchest canines. Dogs were anesthetized, intubated and ventilated. Venous return was drained through caval cannulae into a large volume reservoir (2 1), then forwarded to the right atrium $(R A)$ by means of a roller pump (upper part of the figure). Contrary to the setup shown in Fig. 3, there were no Starling resistors in the circuit (the compliant tube served only to reduce the pressure oscillations generated by the pump). Here, the controlled variable was pump output, which determined ventricular filling. Changing pump output would induce concomitant changes in cardiac output and right atrial pressure. Due to the buffering effect of the reservoir, these modifications would not depend on the particular value of venous return flow (i.e., cardiac function would be uncoupled from venous return function). In this way, cardiac output curves were constructed at different PEEP levels, after surgical closure of the chest (lower part of the figure). Surface pressure over the heart was measured with specialized flat sensors, to allow the calculation of right atrial transmural pressure. Left atrial pressure, also measured in these experiments, is not shown for simplicity (from [28] with permission). Right atrial pressure is measured relative to atmosphere in the left-hand part, and relative to extramural pressure in the right-hand part of the figure These data are discussed in detail in Sect. "Contact interactions of the heart and lungs"

\section{Cardiorespiratory interactions in transient versus steady state}

Whenever considering the interactions of respiration with the function of other organs, it is important to bear in mind the distinction between transient and steady state effects [12]. Transient effects refer either to periodic changes induced by the inspiratory/expiratory cycle (phasic effects) or to unsustained effects of various respiratory maneuvers. Due to the short duration, their mechanisms are of a primarily mechanical nature. Steady state effects indicate the impact of sustained alterations of respiratory conditions, such as the institution of positive end-expiratory pressure (PEEP) in a mechanically ventilated patient. Steady state effects depend both on mechanical and on neurohumoral factors (for example the neural regulation of venous compliance, resistance to venous return and cardiac contractility, Fig. 2e).

A caveat is here in order. In the steady state, venous return is methodologically very hard to dissociate from cardiac function. Again, the construction of a complete venous return curve is impossible without bypassing the right ventricle with an external circuit, and a similar remark applies to the cardiac function curve (Sects. "Venous return curve", "Cardiac function curve"). For these reasons, there is an understandable lack of human data on steady state cardiorespiratory interactions. Furthermore, most available experimental studies have been carried out in animals with normal lungs, and have focused on the effects of high PEEP levels $\left(\geq 15 \mathrm{~cm} \mathrm{H}_{2} \mathrm{O}\right)$ while ignoring those related to tidal inflation. Extrapolation of such data to the clinical setting must therefore be done with some caution.

\section{Respiration and venous return}

Transient effects of practical importance will be discussed in later Sects. (6.1-6.4 in Part II). Here, we shall restrict ourselves to the description of steady state effects. Most of the available relevant studies have been focused on the impact of a steady increase in intrathoracic pressure as effected by positive end-expiratory airway pressure (PEEP).

For decades, it has been conventional wisdom that an essential mechanism whereby PEEP depresses cardiac output consists in the transmission of the elevated mean intrathoracic pressure into the right atrium, which raises intramural RAP and so decreases the pressure gradient for venous return $[6,13]$. The assumption that other determinants of venous return remain unaltered by PEEP was implicit in this reasoning, but is now contradicted by several lines of evidence.

Two independent groups have reported that PEEP levels of up to 15 [14] or $20 \mathrm{~cm} \mathrm{H}_{2} \mathrm{O}$ [15], while clearly depressing cardiac output, caused identical increases in RAP and MSFP, so that the pressure gradient for venous return was invariant, a finding confirmed more recently in humans [16]. The mechanisms involved a transfer of capacitance blood from the unstressed to the stressed volume [15], due to enhancement of venous tone 
mediated in part by sympatho-adrenergic activation [14], akin to changes noted earlier in hypotension produced by hemorrhage [17] or local manipulation of the carotid sinus $[18,19]$. Furthermore, the depression of cardiac output by PEEP was amplified by alpha adrenergic blockade [20]. These data indicate that the reflex matching of the increased RAP by an equivalent increase in MSFP is an important facet of cardiovascular adaptation to PEEP. Part of the PEEP-induced augmentation of MSFP could also be due to purely mechanical factors, such as the translocation of blood from the pulmonary to the systemic capacitance vessels [21-23] or the increase in abdominal pressure (due to diaphragmatic descent) which compresses the splanchnic part of the venous reservoir [24].

Although the MSFP-RAP gradient remained constant, cardiac output was clearly depressed in the aforementioned studies, implying that PEEP modified either the resistance to venous return $\left(R_{\mathrm{v}}\right)$ or the critical pressure $\left(P_{\text {crit }}\right)$. This issue was handled in further experiments by Fessler and coworkers [25], who constructed true venous return curves with and without $10 \mathrm{~cm} \mathrm{H}_{2} \mathrm{O}$ PEEP in closed-chest dogs equipped with a external circuit which bypassed the right ventricle. The main results of this unique study are shown in Fig. 3; PEEP somewhat flattened the portion of the curve to the right of the critical point indicating slightly augmented values of $R_{\mathrm{v}}$, as also found by Nanas et al. [15]. PEEP also increased $P_{\text {crit }}$ and sharply depressed the plateau, indicating a decrease in the maximal value of venous return. These effects might be understood if expansion of the lung by PEEP distorted venous geometry, for example, at the entrance of the venae cavae into the thorax [26], or further upstream in the portal circulation (i.e., compression of the liver by diaphragmatic descent [27]).

In short, the available evidence indicates that PEEP interferes with systemic venous return in a manner more complicated than by just raising RAP. It is important to note that all the aforementioned actions of PEEP must be modulated by the volemic status, although detailed experimental data are scant on this point. In particular, hypovolemia is likely to blunt or even entirely prevent the compensatory rise in MSFP. Conversely, repletion of intravascular volume might make the systemic veins less susceptible to compression, thus minimizing the effects of PEEP on $R_{\mathrm{v}}$ and $P_{\text {crit }}$, as shown in the case of the porcine hepatic circulation [27].

\section{Respiration and cardiac function}

Contact interactions of the heart and lungs

Considering that RAP is measured relative to atmosphere and assuming that respiration should not alter the relationship of transmural filling pressure to cardiac output,
Guyton predicted that changes in intrathoracic pressure (ITP) would cause parallel shifts of the cardiac function curve (i.e., cardiac output plotted against intramural RAP) along the pressure axis (Chap. 24 of [6]). This hypothesis was verified by Marini and coworkers [28] (Fig. 4, lower left) in anesthetized, mechanically ventilated canines, using a bypass circuit from the great veins to the right atrium in order to control the inflow of blood into the heart (Fig. 4, upper part). To allow the most accurate measurement of transmural filling pressures, epicardial fluid-filled flat sensors were positioned over the left and right ventricles. In these experiments, the plots of cardiac output versus transmural RAP or left atrial pressure (LAP) were not modified by PEEP levels of up to $15 \mathrm{~cm} \mathrm{H}_{2} \mathrm{O}$, indicating little modulation of ventricular function per se by these ventilatory conditions, consistent with results by other investigators [29] (Fig. 4, lower right). In the former study, there was evidence that lung inflation "compressed the heart", i.e., imposed a progressive external constraint mediated by local surface pressure on the epicardium, which increased with increasing heart volume. This constraint appeared local and independent of global ITP, since it was not removed by opening the chest and could be elicited by the selective inflation of basal lung segments [30]. The concept of heart compression by the inflated lung is consistent with the small heart size typically observed on chest films in acute asthma. Via dynamic hyperinflation, it could also explain the increase in RAP and pulmonary artery occlusion pressure (PAOP) observed on mild exercise as well as voluntary hyperventilation in patients with obstructive lung disease uncomplicated by pulmonary hypertension or overt heart failure [31].

Ventricular interdependence and left ventricular diastolic function

The right (RV) and left ventricle (LV) are mechanically coupled, because they share a common septum and circumferential fibers, and the expansion of both is constrained by a common pericardium. For these reasons, the diastolic filling of one chamber has direct influence on the geometry and stiffness of the other, a phenomenon known as direct (or parallel) ventricular diastolic interdependence [32].

With phasic respiration, the end-diastolic volumes of both ventricles tend to change in opposite directions [33]. Spontaneous inspiration augments venous return, thus increasing RV filling, which in turn makes the LV stiffer, thus impeding its filling [33, 34]. Lung inflation with positive airway pressure tends to act in an inverse fashion $[35,36]$. These mechanisms imply phasic changes in the diastolic properties of the ventricles. They underly in part the respiratory fluctuations of arterial pressure to be described below, although an equally important role is 
being played in that respect by series interdependence (the propagation of changes in RV output to LV output, due to the series arrangement of both ventricles) [37]. ${ }^{5}$

Encroachment of a dilated RV on LV filling as a steady, rather than transient effect may result from extreme hyperinflation, such as associated with PEEP levels in excess of $20 \mathrm{~cm} \mathrm{H}_{2} \mathrm{O}$ [40], or when more moderate increases of ITP and lung volume are superimposed on either an obstructed pulmonary circulation or a failing RV [41]. In these cases, the primum movens is the acute increase in RV afterload, with consequent RV dilatation.

\section{Ventricular afterload}

Defined as the force opposing ejection, ${ }^{6}$ ventricular afterload is represented by the level of transmural pressure, in the course of systole, within either the aortic root (LV afterload) or the pulmonary artery trunk (RV afterload) The transmural rather than the intraluminal pressure must be considered [44, 45], because these great vessels as well as the ventricles are exposed to an extramural pressure (i.e., ITP) which is usually non atmospheric. The mechanisms whereby respiration interacts with LV and $\mathrm{RV}$ afterload are different.

\section{LV afterload}

At the onset of spontaneous inspiration, the intraluminal pressure in the aortic root decreases less than does ITP, due to the connection of this vessel with extrathoracic arteries. As a result, aortic transmural pressure increases. With spontaneous breathing therefore, LV afterload is greater in inspiration than in expiration [46-48]. A symmetrical chain of events leads to a reduced LV afterload in the course of a transient increase in ITP, such as with positive pressure inflation of the lungs. Steady increases in ITP, as effected with PEEP, similarly unload the LV

\footnotetext{
${ }^{5} \mathrm{~A}$ further factor which modulates the impact of respiration on $\mathrm{LV}$ filling is the influence of lung inflation on pulmonary blood volume and pulmonary venous outflow. Experiments in isolated lungs [38, 39] have indicated that, whether actuated by positive airway or negative pleural pressure, an increase in lung volume can "squeeze" blood out of the pulmonary vascular bed, provided that intra-alveolar vessels are filled at end-expiration, which usually requires a left atrial pressure $>3-5 \mathrm{mmHg}$ (more rigorously, West zone 3 conditions, see Sect. "RV afterload" for definition of West zones, and detailed discussion of this issue in [39].

${ }^{6} \mathrm{~A}$ useful simplification. More rigorously, ventricular afterload is defined as the systolic wall stress $(\sigma)$, linked to transmural ejection pressure $(P)$, chamber radius $(r)$, and wall thickness $(h)$ by the Laplace relationship $\sigma=P \times r / h$ [42]. Ejection pressure is in turn linked to arterial impedance, which measures the degree to which the arterial system opposes pulsatile blood flow [43].
}

with potentially beneficial consequences in presence of left heart failure, as described in greater detail below (Sect. "Effects of PEEP on cardiac output" in Part II). Conversely, patients with obstructive sleep apnea have bouts of greatly negative ITP which increase LV afterload, thus contributing to LV hypertrophy [49].

\section{$R V$ afterload}

A seminal paper by Permutt [50] shows that RV afterload is highly dependent on and increases with the proportion of lung tissue in West zone 1 or 2, as opposed to zone 3 conditions. Zones 1 or 2 exist whenever the extraluminal pressure of alveolar capillaries (which is close to alveolar pressure, $P_{\mathrm{A}}$ ) exceeds the intraluminal value, leading to vessel compression. In zone 3 by contrast, intraluminal capillary pressure exceeds $P_{\mathrm{A}}$. For hydrostatic reasons, zones 1 and 2 are more likely to occur in nondependent parts of the lung. Furthermore, respiratory changes in the intraluminal pressure of alveolar capillaries tend to track changes in ITP $^{7}$ and thus to decrease more than does $P_{\mathrm{A}}$ during a spontaneous inspiration and to increase less than does PA on inflation of the lung with positive pressure. Thus, any increase in lung volume, whether in the context of spontaneous [51] or mechanically assisted breathing [45], has the potential to promote the formation of zones 1 and 2 at the expense of zone 3, and thus to increase RV afterload. These considerations are of high clinical relevance, notably concerning the possible induction or aggravation of acute cor pulmonale by mechanical ventilation, as described below (Sect. "Mechanical ventilation and acute cor pulmonale" in Part II).

\section{Myocardial contractility}

Some studies have indicated that lung inflation by PEEP could trigger the humoral release of one or several cardiodepressor agents $[52,53]$. However, as we have already seen, biventricular Starling curves were not depressed by PEEP (Fig. 4, right). Furthermore, work in both animals and humans, using various methodologies to measure the size of cardiac chambers, consistently failed to indicate any influence of PEEP on the relationship of ventricular preload to stroke output, stroke work, or end-systolic ventricular pressure [40, 41, 54, 55]. Finally, experimental studies have shown that end-systolic elastance, a recognized load-invariant index of contractility, remained constant at levels of PEEP up to $15 \mathrm{~cm} \mathrm{H}_{2} \mathrm{O}[55,56]$, even when possible adrenergic reflexes were suppressed with beta-blockade [55]. In short, a steady state increase in ITP

\footnotetext{
${ }^{7}$ This is because the alveolar capillaries are in continuity with the pulmonary artery trunk, where intraluminal pressure decreases when ITP decreases, and increases when ITP increases.
} 
and lung volume, as effected by PEEP, does not appear to directly depress myocardial contractility.

Myocardial perfusion and ischemia

Whether in specific conditions PEEP could indirectly alter myocardial contractility by inducing myocardial ischemia remains largely unresolved $[57,58]$. Many studies have indicated that clinically relevant levels of PEEP can decrease myocardial blood flow. In the LV, afterload and preload are concomitantly reduced, leading to diminished systolic wall stress and $\mathrm{O}_{2}$ demand, with an unpredictable net effect on the adequacy of myocardial $\mathrm{O}_{2}$ supply [59, 60]. In a dog model of acute ischemic LV failure induced by embolization of the left coronary artery with microspheres, the institution of $15 \mathrm{~cm} \mathrm{H}_{2} \mathrm{O}$ PEEP had no impact on ischemic myocardial metabolism assessed by lactate extraction [61]. In the RV by contrast, PEEP has a greater potential to upset the balance between $\mathrm{O}_{2}$ supply and demand, due to its ability to increase afterload.
Indeed, two canine studies have shown that the institution of PEEP aggravates the RV dysfunction induced by ligation of the right coronary artery [41, 62]. In one of them, PEEP also caused an extension of myocardial necrosis in the area at risk [62].

There is evidence that negative ITP can induce or aggravate LV myocardial ischemia, likely by increasing LV afterload in the presence of insufficient coronary reserve. Scharf and colleagues [63] found that patients with coronary artery disease developed LV dyskinesis during a Mueller maneuver with an inspiratory effort of -20 to $-30 \mathrm{~cm} \mathrm{H}_{2} \mathrm{O}$. These changes were not seen in patients with normal coronary arteries. Negative ITP of this magnitude can occur during weaning from mechanical ventilation, at times inducing LV dysfunction possibly due to LV ischemia and responsible for weaning failure (Part II, Sect. "Weaning failure from cardiovascular origin").

Acknowledgments We warmly thank the reviewers for their contribution to this text, in the form of numerous thoughtful, in depth, and very constructive comments.

\section{References}

1. Wise RA (1994) Historical perspectives on the mechanical interactions of respiration and circulation. In: Perret $\mathrm{C}$ (ed) Les interactions cardiopulmonaires. Arnette, Paris, pp 3-15

2. Farhi LE (1990) World War II and respiratory physiology: the view from Rochester, New York. J Appl Physiol 69:1565-1570

3. Carr DT, Essex HE (1945) Certain effects of positive pressure respiration on the circulatory and respiratory systems. Am Heart J 8:53-72

4. Otis AB, Rahn H, Brontman M, Mullins LJ, Fenn WO (1946)

Ballistocardiographic study of changes in cardiac output due to respiration. J Clin Invest 25:413-421

5. Cournand A, Motley HL, Werko L, Richards DW (1948) Physiological studies of the effects of intermittent positive pressure breathing on cardiac output in man. Am J Physiol 152:162174

6. Guyton AC, Jones CE, Coleman TG (1973) Circulatory physiology: cardiac output and its regulation. Saunders, Philadelphia

7. Rothe CF (1983) Venous system: physiology of the capacitance vessels. In: Shepherd JT, Abboud FM (eds) Handbook of physiology: the cardiovascular system vol. 3: peripheral circulation and organ blood flow, Part 1. American Physiological Society, Bethesda, pp 397-452
8. Magder S (1994) Venous return and cardiac output. In: Perret C, Feihl F (eds) Les interactions cardio-pulmonaires. Arnette, Paris, pp 29-36

9. Magder S (2006) Point: the classical Guyton view that mean systemic pressure, right atrial pressure, and venous resistance govern venous return is/is not correct. J Appl Physiol 101:1523-1525

10. Guyton AC, Lindsey AW, Abernathy B, Langston JB (1958) Mechanism of increased venous return and cardiac output caused by epinephrine. Am J Physiol 192:126-130

11. Caldini P, Permutt S, Waddell JA, Riley RL (1974) Effect of epinephrine on pressure, flow, and volume relationships in the systemic circulation of dogs. Circ Res 34:606-623

12. Fessler HE (1997) Heart-lung interactions: applications in the critically ill. (Review) (105 refs). Eur Respir J 10:226-237

13. Qvist J, Pontoppidan H, Wilson RS, Lowenstein E, Laver MB (1975) Hemodynamic response to mechanical ventilation with PEEP: the effect of hypervolemia. Anesthesiology 42:45-55

14. Fessler HE, Brower RG, Wise RA, Permutt S (1991) Effects of positive end-expiratory pressure on the gradient for venous return. Am Rev Respir Dis 143:19-24
15. Nanas S, Magder S (1992) Adaptations of the peripheral circulation to PEEP. Am Rev Respir Dis 146:688-693

16. Jellinek H, Krenn H, Oczenski W, Veit F, Schwarz S, Fitzgerald RD (2000) Influence of positive airway pressure on the pressure gradient for venous return in humans. J Appl Physiol 88:926-932

17. Rothe CF, Drees JA (1976) Vascular capacitance and fluid shifts in dogs during prolonged hemorrhagic hypotension. Circ Res 38:347-356

18. Shoukas AA, Sagawa K (1973) Control of total systemic vascular capacity by the carotid sinus baroreceptor reflex. Circ Res 33:22-33

19. Deschamps A, Magder S (1992) Baroreflex control of regional capacitance and blood flow distribution with or without alpha-adrenergic blockade. Am J Physiol 263(6 Pt 2):H1755-H1763

20. Scharf SM, Ingram RH (1977) Influence of abdominal pressure and sympathetic vasoconstriction on the cardiovascular response to positive endexpiratory pressure. Am Rev Respir Dis 116:661-670

21. Mitzner W, Goldberg H, Lichtenstein S (1976) Effect of thoracic blood volume changes on steady state cardiac output. Circ Res 38:255-261

22. Risoe C, Hall C, Smiseth OA (1991) Splanchnic vascular capacitance and positive end-expiratory pressure in dogs. J Appl Physiol 70:818-824 
23. Peters J, Hecker B, Neuser D, Schaden W (1993) Regional blood volume distribution during positive and negative airway pressure breathing in supine humans. J Appl Physiol 75:1740-1747

24. Van Den Berg PCM, Jansen JRC, Pinsky MR (2002) Effect of positive pressure on venous return in volumeloaded cardiac surgical patients. J Appl Physiol 92:1223-1231

25. Fessler HE, Brower RG, Wise RA, Permutt S (1992) Effects of positive end-expiratory pressure on the canine venous return curve. Am Rev Respir Dis 146:4-10

26. Fessler HE, Brower RG, Shapiro EP, Permutt S (1993) Effects of positive end-expiratory pressure and body position on pressure in the thoracic great veins. Am Rev Respir Dis 148:1657-1664

27. Brienza N, Revelly JP, Ayuse T, Robotham JL (1995) Effects of PEEP on liver arterial and venous blood flows. Am J Respir Crit Care Med 152:504-510

28. Marini JJ, Culver BH, Butler J (1981) Effect of positive end-expiratory pressure on canine ventricular function curves. J Appl Physiol 51:1367-1374

29. Wise RA, Robotham JL, BrombergerBarnea B, Permutt S (1981) Effect of PEEP on left ventricular function in right-heart-bypassed dogs. J Appl Physiol 51:541-546

30. Marini JJ, Culver BH, Butler J (1981) Mechanical effect of lung distention with positive pressure on cardiac function. Am Rev Respir Dis 124:382386

31. Butler J, Schrijen F, Henriquez A, Polu JM, Albert RK (1988) Cause of the raised wedge pressure on exercise in chronic obstructive pulmonary disease. Am Rev Respir Dis 138:350-354

32. Janicki JS, Weber KT (1980) Factors influencing the diastolic pressurevolume relation of the cardiac ventricles. [Review] [44 refs]. Fed Proc 39:133-140

33. Scharf SM (1992) Cardiopulmonary interactions. In: Scharf SM (ed) Cardiopulmonary physiology in critical care. Marcel Dekker, New York, pp 333-355

34. Kim BH, Ishida Y, Tsuneoka Y, Matsubara N, Hiraoka T, Takeda H, Inoue M, Kamada T, Kimura K, Kozuka T (1987) Effects of spontaneous respiration on right and left ventricular function: evaluation by respiratory and ECG gated radionuclide ventriculography. J Nucl Med 28:173177

35. Santamore WP, Heckman JL, Bove AA (1983) Cardiovascular changes from expiration to inspiration during IPPV. Am J Physiol 245:H307-H312
36. Mitchell JR, Whitelaw WA, Sas R, Smith ER, Tyberg JV, Belenkie I (2005) RV filling modulates LV function by direct ventricular interaction during mechanical ventilation. Am J Physiol 289:H549H557

37. Olsen CO, Tyson GS, Maier GW, Spratt JA, Davis JW, Rankin JS (1983) Dynamic ventricular interaction in the conscious dog. Circ Res 52:85-104

38. Permutt S, Howell JB, Proctor DF, Riley RL (1961) Effect of lung inflation on static pressure-volume characteristics of pulmonary vessels. J Appl Physiol 16:64-70

39. Brower R, Wise RA, Hassapoyannes C, Bromberger-Barnea B, Permutt S (1985) Effect of lung inflation on lung blood volume and pulmonary venous flow. J Appl Physiol 58:954-963

40. Jardin F, Farcot JC, Boisante L, Curien N, Margairaz A, Bourdarias JP (1981) Influence of positive end-expiratory pressure on left ventricular performance. N Engl J Med 304:387-392

41. Schulman DS, Biondi JW, Zohgbi S, Cecchetti A, Zaret BL, Soufer R (1992) Left ventricular diastolic function during positive end-expiratory pressure. Impact of right ventricular ischemia and ventricular interaction. Am Rev Respir Dis 145:515-521

42. Opie L (1997) Ventricular function, Chap. 12. In: Opie L (ed) The heart: physiology, from cell to circulation. Lippincott-Raven, Philadelphia, pp 391-420

43. Nichols WW, O’Rourke MF (1990) Vascular impedance. McDonald's blood flow in arteries, Chap. 11. Edward Arnold, London, pp 283-329

44. Scharf SM, Brown R, Tow DE, Parisi AF (1979) Cardiac effects of increased lung volume and decreased pleural pressure in man. J Appl Physiol 47:257-262

45. Jardin F, Delorme G, Hardy A, Auvert B, Beauchet A, Bourdarias JP (1990) Reevaluation of hemodynamic consequences of positive pressure ventilation: emphasis on cyclic right ventricular afterloading by mechanical lung inflation. Anesthesiology 72:966-970

46. Buda AJ, Pinsky MR, Ingels NB Jr, Daughters GT 2nd, Stinson EB, Alderman EL (1979) Effect of intrathoracic pressure on left ventricular performance. N Engl J Med 301:453-459

47. Pinsky MR, Summer WR, Wise RA, Permutt S, Bromberger-Barnea B (1983) Augmentation of cardiac function by elevation of intrathoracic pressure. J Appl Physiol 54:950-955
48. Peters J, Kindred MK, Robotham JL (1988) Transient analysis of cardiopulmonary interactions. II Systolic events. J Appl Physiol 64:1518-1526

49. Naughton MT, Bradley TD (1998) Sleep apnea in congestive heart failure. Clin Chest Med 19:99-113

50. Permutt S, Bromberger-Barnea B, Bane HN (1962) Alveolar Pressure, pulmnary venous pressure, and the vascular waterfall. Med Thorac 19:239-260

51. Jardin F, Farcot JC, Boisante L, Prost JF, Gueret P, Bourdarias JP (1982) Mechanism of paradoxic pulse in bronchial asthma. Circulation 66:887894

52. Manny J, Grindlinger G, Mathe AA, Hechtman HB (1978) Positive endexpiratory pressure, lung stretch, and decreased myocardial contractility. Surgery 84:127-133

53. Grindlinger GA, Manny J, Justice R, Dunham B, Shepro D, Hechtman HB (1979) Presence of negative inotropic agents in canine plasma during positive end-expiratory pressure. Circ Res 45:460-467

54. Calvin JE, Driedger AA, Sibbald WJ (1981) Positive end-expiratory pressure (PEEP) does not depress left ventricular function in patients with pulmonary edema. Am Rev Respir Dis 124:121128

55. Johnston WE, Vinten-Johansen J, Santamore WP, Case LD, Little WC (1989) Mechanism of reduced cardiac output during positive end-expiratory pressure in the dog. Am Rev Respir Dis 140:1257-1264

56. Crottogini AJ, Willshaw P, Barra JG, Breitbart GJ, Pichel RH (1988) Endsystolic pressure-volume relationships in dogs during ventilation with PEEP. Am J Physiol 254(4 Pt 2):H664-H670

57. Scharf SM (2001) Ventilatory support in the failing heart. In: Scharf SM, Pinsky MR, Magder S (eds) Respiratory-circulatory interactions in health and disease. Marcel Dekker, New York, pp 519-550

58. Fessler HE (2001) Mechanical ventilation with PEEP. In: Scharf SM, Pinsky MR, Magder S (eds) Respiratory-circulatory interactions in health and disease. Marcel Dekker, New York, pp 807-836

59. Tucker HJ, Murray JF (1973) Effects of end-expiratory pressure on organ blood flow in normal and diseased dogs. $\mathbf{J}$ Appl Physiol 34:573-577

60. Hevroy O, Grundnes O, Bjertnaes L, Mjos OD (1989) Myocardial blood flow and oxygen consumption during positive end-expiratory pressure ventilation at different levels of cardiac inotropy and frequency. Crit Care Med $17: 48-52$ 
61. Hevroy O, Reikeras O, Grundnes O, Mjos OD (1988) Cardiovascular effects of positive end-expiratory pressure during acute left ventricular failure in dogs. Clin Physiol 8:287-301
62. Johnston WE, Vinten-Johansen J, Shugart HE, Santamore WP (1992) Positive end-expiratory pressure potentiates the severity of canine right ventricular ischemia-reperfusion injury. Am J Physiol 262(1 Pt 2):H168-H176
63. Scharf SM, Bianco JA, Tow DE, Brown $R$ (1981) The effects of large negative intrathoracic pressure on left ventricular function in patients with coronary artery disease. Circulation 63:871-875 